\title{
Accelerated Orthodontic Tooth Movement in Adult Patients by Micro- Perforations of Cortical Bone
}

\author{
Tina Mahmoudi ${ }^{1}$, Robert Laraway ${ }^{4}$, Ahmed Al-Sinan ${ }^{5}$, Ahmad Roosta ${ }^{3}$, Eung-Kwon Pae ${ }^{2}$ and Monica Schneider ${ }^{2 *}$ \\ ${ }^{1}$ Private practice in Orthodontics, Baltimore MD, USA \\ ${ }^{2}$ Department of Orthodontics and Pediatric Dentistry, School of Dentistry, University of Maryland, Baltimore MD, USA \\ ${ }^{3}$ Private practice in General Dentistry, Baltimore MD, USA \\ ${ }^{4}$ Private practice in Orthodontics, Denton MD, USA \\ ${ }^{5}$ Ministry of Health, Dammam, Saudi Arabia
}

*Corresponding author: Monica Schneider, Department of Orthodontics and Pediatric Dentistry, School of Dentistry, University of Maryland, Baltimore MD, 21201, USA, E-mail: mschneider@umaryland.edu

Received: 30 Oct, 2018 | Accepted: 16 Nov, 2018 | Published: 22 Nov, 2018

Citation: Mahmoudi T, Laraway R, Al-Sinan A, Roosta A, Pae EK, et al. (2018) Accelerated Orthodontic Tooth Movement in Adult Patients by Micro-Perforations of Cortical Bone. Int J Dent Oral Health 5(1): dx.doi.org/10.16966/2378-7090.281

Copyright: (c) 2018 Mahmoudi T, et al. This is an open-access article distributed under the terms of the Creative Commons Attribution License, which permits unrestricted use, distribution, and reproduction in any medium, provided the original author and source are credited.

\section{Abstract}

Introduction: The objective of this study was to determine whether micro-osteoperforations of cortical bone produce accelerated tooth movement during space closure in adult patients.

Methods: Ten healthy adult patients, ages 18 to 37 years old requiring maxillary first premolar extractions participated in this split-mouth study. Temporary Anchorage Devices (TADs) were placed bilaterally for anchorage control. Micro-osteoperforations were performed unilaterally and ipsilateral maxillary canines were distalized using sliding mechanics. Canine retraction rate was measured using: (1) Cone Beam Computed Tomography (CBCT) and (2) Digital models taken before canine distalization at the initiation of the study $\left(\mathrm{T}_{0}\right)$ and three months later $\left(\mathrm{T}_{1}\right)$.

Results: Mean space closure on the micro-osteoperforation side was $0.44 \mathrm{~mm}$ less for TAD-Upper canine distal measurement, $0.30 \mathrm{~mm}$ greater for Upper $2^{\text {nd }}$ premolar mesial to Upper canine distal measurement on CBCT. Space closure on the micro-osteoperforation side was $0.14 \mathrm{~mm}$ greater for Upper canine Cusp Tip-Upper second premolar Cusp Tip, $0.24 \mathrm{~mm}$ less for Upper second premolar mesial to Upper canine distal measurement, $0.24 \mathrm{~mm}$ greater for Upper lateral Midpoint-Upper canine Cusp Tip, $0.18 \mathrm{~mm}$ greater for Upper molar mesio-palatal Cusp Tip-Upper canine Cusp Tip on digital models. Space closure on the Micro-osteoperforations side was not statistically significant for any variable (t-test $p>0.05)$.

Conclusion: Our results indicate that canine retraction is very variable on the experimental side when compared to the control side over the treatment time and the increase in the rate of tooth movement was not significantly different in the overall sample. Further studies are necessary to evaluate the effects of micro-osteoperforations on the rate of tooth movement in the orthodontic treatment of adult patients.

Keywords: Accelerated tooth movement; Corticotomy; Micro-osteoperforations; Orthodontics

\section{Introduction}

The duration of active orthodontic treatment is significant factors in decision making to both the patient and the orthodontist. The number of adult patients seeking orthodontic treatment has grown over the years and this trend is likely to increase, as adult patients are more concerned about esthetics. The 2014 AAO Economics of Orthodontics survey results indicated that 27 percent of orthodontic patients are age 18 or more, this shows an increase from 21 percent in 2012. Treatment of adult patients takes longer especially if space closure after tooth extractions is needed for best outcomes. The average length of orthodontic treatment for adult patients is between 18 to 30 months (AAO, 2007). Therefore, there is a growing need to reach satisfactory treatment results in as little time as possible.

Dental crowding and/or protrusive dental relationships frequently require the extractions of two maxillary and two mandibular premolars. A critical stage in the correction of dental crowding or protrusion is the retraction of the canines through the first premolar extraction spaces. Variables such as force magnitude, duration, initial tooth displacement, and biologic changes of the periodontium amongst others must be considered to obtain optimal tooth movement. Nonetheless, space closure in adult patients presents unique challenges to practitioners due to age-related changes. These challenges can include but are not limited to reduced bone response to mechanical forces, increased risk of attachment and bone loss, greater bone resistance to forces due to medications, and etc.

Orthodontic tooth movement is directly associated with bone remodeling [1]. It has been suggested that the accelerated tooth movement might be due to a demineralization-remineralization process known as the Regional Acceleratory Phenomenon (RAP) [2]. Any stimulus that increases bone turnover and decreases bone density appears to result in faster tooth movement [3]. Higher concentration of inflammatory cytokines such as IL-1, TNF- $\alpha$, 
IL-6, IL-8, and IL-11 have been found in gingival crevicular fluid surrounding the teeth intended to move orthodontically [4]. Soon after forces are applied on a tooth, expression of these cytokines increases which in turn leads to stimulation of osteoclast differentiation and activation of bone remodeling and tooth movement. Inhibiting the expression of these specific cytokines can lead to a reduced rate of orthodontic tooth movement [5,6]. Teixeira, et al. [7] investigated the cytokine expression and tooth movement after performing shallow perforations in the cortical bone of adult Sprague-Dawley rats. They reported that shallow perforations of the cortical plate increased the levels of cytokine expression in response to orthodontic forces in the experimental group, which indicated accelerated bone remodeling and increased rate of tooth movement. A similar study by Kim, et al. [8] using piezopuncture in dogs reported a significantly greater tooth movement on treated sites; yet, the difference of $1.6 \mathrm{~mm}$ over 6 months in maximum was questionable as for clinical effectiveness from a costand-effect point of view.

To date, several studies have shown the effect of numerous surgical and non-surgical techniques on the expression of inflammatory markers that play a significant role accelerating tooth movement [9-17]. It has also been reported that micro-osteoperforations of the cortical bone are as effective as corticision to accelerate tooth movement in rats [18]. Alikhani, et al. [19] performed a single center single blinded study to investigate the effect of microosteoperforations on the rate of tooth movement in human subjects. This study concluded that the micro-osteoperforations accelerate tooth movement and can reduce the orthodontic treatment time significantly. However; this was the only study investigating microosteoperforations on human subjects. Therefore, a lack of research on the effectiveness of micro-osteoperforations in accelerating tooth movement in orthodontic patients is still evident. This study intends to further examine the effectiveness of using micro-osteoperforations as a flapless and minimally invasive procedure to enhance orthodontic tooth movement in adult patients.

\section{Material and Methods}

Approval to conduct this split-mouth pilot study was obtained from the Human Research Protections Office (HRPO) of University of Maryland Institutional Review Board (IRB) HP-00055763. Ten healthy adult patients between the ages of 18 to 37 seeking orthodontic treatment met the inclusion criteria and completed the informed consent (Table 1).

All patients required extraction of bilateral maxillary first premolars and subsequent maxillary canine retraction to close the extraction space as part of their orthodontic treatment. Patients were bonded with 0.022 slot Unitek brackets (Victory Series ${ }^{\text {Tw }}$ Miniature Metal Bracket System or Clarity Ceramic Brackets with metal slot) and were referred for extraction of the maxillary first premolars. After the initial leveling and alignment stage, RMO Dual-Top Temporary Anchorage Device (TAD) of $1.6 \mathrm{~mm}$ of diameter and $6 \mathrm{~mm}$ in length were placed bilaterally mesial to the maxillary first molars in order to maintain adequate anchorage. The maxillary first molars were connected to the TAD for stabilization for indirect anchorage. A maxillary only CBCT was obtained to evaluate TAD placement and location of canine crown and root. Intra-oral photographs and alginate impressions for digital study models were also taken before starting the canine retraction $\left(\mathrm{T}_{0}\right)$ and at the conclusion of the study $\left(\mathrm{T}_{1}\right)$. The impressions were poured up immediately with Whip Mix orthodontic stone, labeled, dated, and scanned by OrthoCast model lab. The CBCT and digital models provided a baseline for future measurements.
Table 1: Inclusion and exclusion criteria for the study.

\begin{tabular}{|l|l|}
\hline \multicolumn{1}{|c|}{ Inclusion Criteria } & \multicolumn{1}{c|}{ Exclusion Criteria } \\
\hline $\begin{array}{l}\text { Healthy adult patients 18-44 yrs } \\
\text { of age }\end{array}$ & $\begin{array}{l}\text { Medical history of immune } \\
\text { disorders or radiation therapy }\end{array}$ \\
\hline $\begin{array}{l}\text { Minor to moderate crowding (up } \\
\text { to } 6 \mathrm{~mm} \text { ) }\end{array}$ & $\begin{array}{l}\text { Severe crowding (greater than } \\
6 \mathrm{~mm} \text { ) }\end{array}$ \\
\hline $\begin{array}{l}\text { No current active periodontal } \\
\text { disease }\end{array}$ & Current active periodontal disease \\
\hline $\begin{array}{l}\text { Orthodontic treatment plan } \\
\text { requiring removal of bilateral first } \\
\text { maxillary premolars }\end{array}$ & $\begin{array}{l}\text { Patients who require prophylactic } \\
\text { antibiotics }\end{array}$ \\
\hline
\end{tabular}

The investigator (T.M) performed three manual microosteoperforations using the PROPEL'System (Propel Orthodontics, the Excellerator) adhering to the following protocol: Rinse with Chlorhexidine Digluconate $0.2 \% \mathrm{w} / \mathrm{v}$ antiseptic mouthwash for 60 seconds prior to the procedure. Apply local infiltrative anesthesia (2\% Lidocaine with 1/100000 Epinephrine). Perform three microosteoperforations of approximately $5 \mathrm{~mm}$ in depth and $1.5 \mathrm{~mm}$ in diameter distal to the maxillary canines in the extraction space. Rinse with Chlorexidine Digluconate $0.2 \%$ w/v antiseptic mouthwash for 60 seconds after the procedure is complete.

Canine retraction was performed using a $0.017 \times 0.025$ stainless steel working arch wire. Nickel titanium closed coil springs (SentalloyGAC International) were placed from the canine bracket hook to the first molar bilaterally. The force from the coil spring was measured with a Correx gram force gauge to deliver $150 \mathrm{~g}$ of force, which is the adequate force magnitude for retraction (Figure 1). The force produced by the coil was verified and the appliances were examined for any distortion or change in position at each visit. Final records (CBCT, intra-oral photographs, and digital models) were taken three months after starting space closure $\left(\mathrm{T}_{1}\right)$.

Cone Beam Computed Tomography image was obtained using the iCAT scanner (Imaging Sciences International, Hatfield, PA, USA) available at The University of Maryland School of Dentistry. All the CBCT images were taken by the same person and the CBCT parameters and patient's position were identical in all the scans. The scans were taken with the patient's head upright. Images were taken both before the micro-osteoperforation procedure $\left(\mathrm{T}_{0}\right)$ and after three months of canine retraction at the conclusion of the study $\left(\mathrm{T}_{1}\right)$. To perform more accurate measurements and avoid superimposition, only onesided cephalograms were used in this study. Anatomage Invivo 5 3D software was used to create right and left side cephalometric $\mathrm{x}$-rays from the initial and final CBCTs for each subject. Alginate models taken at the initial and final appointments $\left(\mathrm{T}_{0}\right.$ and $\left.\mathrm{T}_{1}\right)$ were scanned and digitized. The scanned models were used to measure the maxillary canine movement. Table 2, figures 2 and 3 show a summary of all the measurements performed and their abbreviations.

To quantify the distance of tooth movement in millimeters, two sets of two measurements were performed at $\mathrm{T}_{0}$ and $\mathrm{T}_{1}$ by two different examiners who were blinded to the study and the average of the two measurements was taken and used in the statistical analysis.

\section{Statistical Analysis}

All the acquired data was analyzed using the STATA statistical software (version 10). Skewness and Kurtosis for normality were 

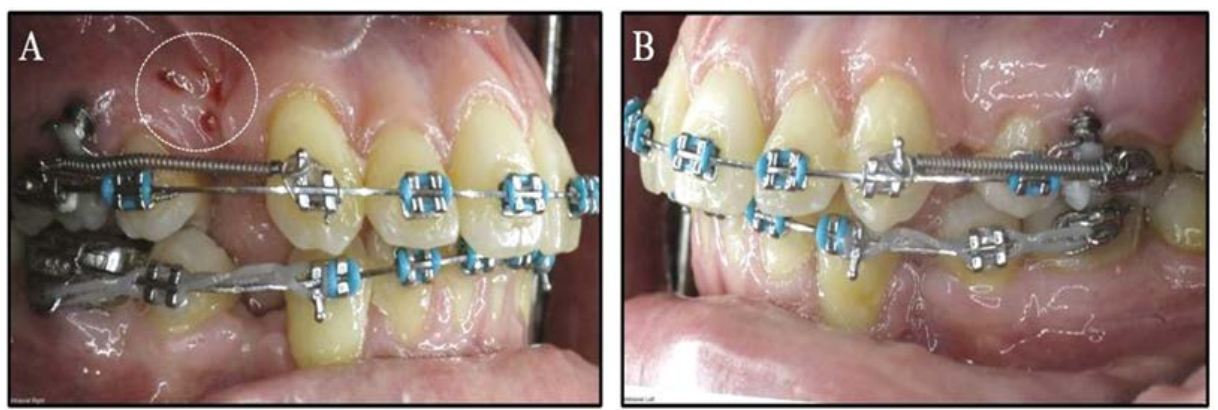

Figure 1: Intra- oral photographs taken at initiation of the canine retraction $\left(T_{1}\right)(A)$ Experimental side showing three micro-osteoperforations at the extraction site (white circle) and nickel-titanium coil spring from the canine bracket hook to the first molar. (B) Control side showing the nickeltitanium coil spring and no micro-osteoperforations at the extraction site.

A

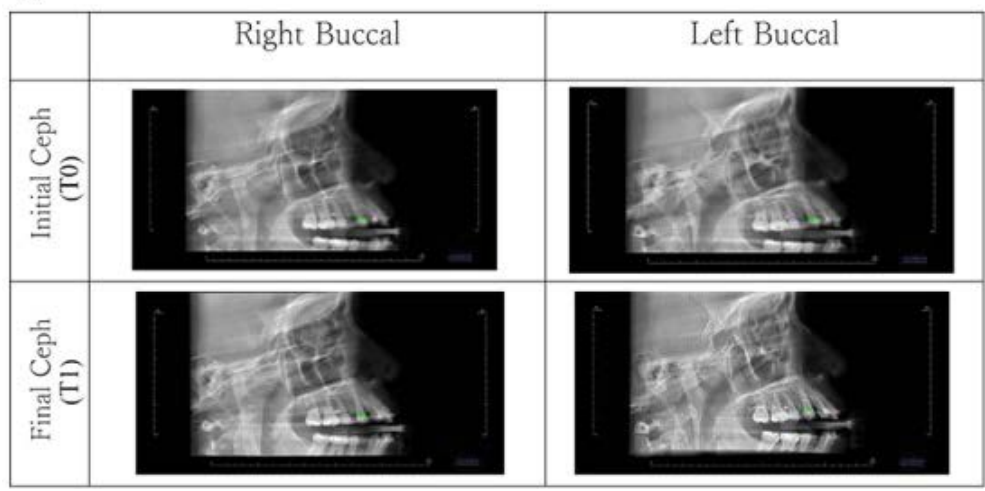

B

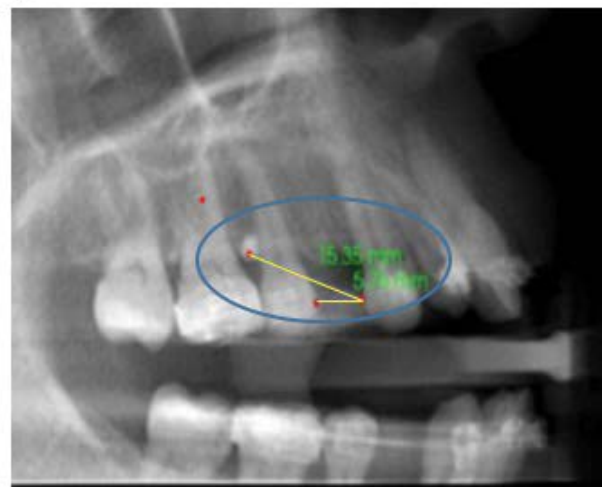

Figure 2: (A) Unilateral right and left sided cephalograms created by Anatomage Invivo5 3D software at T0 and T1 (B) Measurements performed on $\mathrm{CBCT}$.

\begin{tabular}{|c|c|c|c|c|}
\hline & Right Buccal & $\begin{array}{l}\text { Occlusal } \\
\text { U3 Cusp Tip-U5 Cusp Tip (mm) } \\
\text { U2 Midpoint-U3 Cusp Tip (mm) }\end{array}$ & $\begin{array}{c}\text { Occlusal } \\
\text { U5M-U3D (mm) } \\
\text { U6 MP Cusp Tip-U3 Cusp Tip (mm) }\end{array}$ & Left Buccal \\
\hline $\begin{array}{l}\text { Initial } \\
\text { (T0) }\end{array}$ & & & & \\
\hline $\begin{array}{r}\text { Final } \\
(\mathrm{T} 1)\end{array}$ & & & & \\
\hline
\end{tabular}

Figure 3: All digital model measurements. 
Table 2: List of Anatomage In vivo 5 3D and OrthoCAD 3.5 Cadent ${ }^{\mathrm{TM}}$ abbreviations and measurements.

\begin{tabular}{|c|c|c|}
\hline & Abbreviation & Measurement \\
\hline \multirow[b]{2}{*}{ Anatomage Invivo 5 3D } & TAD-U3D (mm) & $\begin{array}{l}\text { The distance from the TAD to the most outer point of the distal curvature of the } \\
\text { maxillary canine }\end{array}$ \\
\hline & U5M-U3D (mm) & $\begin{array}{l}\text { The distance from the most outer point of the mesial curvature of the maxillary } \\
\text { second premolar and the distal most out point of the curvature of the maxillary } \\
\text { canine }\end{array}$ \\
\hline \multirow{4}{*}{$\begin{array}{l}\text { OrthoCAD } 3.5 \\
\text { Cadent }^{\mathrm{TM}}\end{array}$} & U3 Cusp Tip-U5 Cusp Tip (mm) & $\begin{array}{l}\text { The distance from the cusp tip of the maxillary canine to the buccal cusp tip of } \\
\text { the maxillary second premolar }\end{array}$ \\
\hline & U5M-U3D (mm) & $\begin{array}{l}\text { The distance from the distal wall of the maxillary canine to the mesial wall of the } \\
\text { maxillary second premolar }\end{array}$ \\
\hline & U2 Midpoint- U3 Cusp Tip (mm) & $\begin{array}{l}\text { The distance from a midpoint on the incisal edge of the maxillary lateral incisor } \\
\text { to the maxillary canine cusp tip }\end{array}$ \\
\hline & U6 MP Cusp Tip-U3 Cusp Tip (mm) & $\begin{array}{l}\text { The distance from the mesio-palatal Cusp tip of the maxillary first molar to the } \\
\text { cusp tip of the maxillary canine }\end{array}$ \\
\hline
\end{tabular}

examined for each of the six measurements (two CBCT measurements and four digital model measurements) and all the parameters showed normal distribution. In addition, intra-examiner reliability was tested for each of the six measurements performed by each examiner using Student t-tests to compare the compatibility between their measurements. Six random patients were chosen for each measurement and the $\mathrm{P}<0.05$ was considered to be significant for statistical inferences. Paired Student t-tests were performed for the six measurements to compare the average rate of space closure in the experimental side, the side treated with micro-osteoperforations, versus the control side. One-tailed $\mathrm{P}$ values were also calculated and $\mathrm{P}<0.05$ was determined to be for the level of statistical significance. A group difference was expressed by mean \pm 1 standard deviation (SD).

\section{Results}

Ten healthy adult patients between the ages of 18-37 were recruited from University of Maryland School of Dentistry, Orthodontic Department's patient pool. All of these patients had a malocclusion that required extraction of maxillary first premolars as part of their treatment plan. The ten subjects initiated the experimental phase and completed the study with no loss to follow-up. All patients maintained good oral hygiene throughout the study and took no medications including anti-inflammatory analgesics before and during the period of the study. The age range of the study subjects was from 18 to 37 years with the mean of 25.5 years, eight subjects were females and two were males: six African American, two Caucasian, one Asian, and one Hispanic.

Canine retraction was measured on each patient on both experimental and control side by two calibrated examiners at $\mathrm{T}_{0}$ and $\mathrm{T}_{1}$ on CBCTs and digital models. An average of the two obtained measurements for each category was used for statistical analysis. Skewness test for each of the six measurements was between -0.5 and 0.5 indicating that the distribution was approximately symmetric and it was appropriate to use paired t-test for statistical analysis. Also, the intra-examiner reliability test for each of the six measurements showed not significant differences between the $1^{\text {st }}$ and $2^{\text {nd }}$ measurements $(\mathrm{p} \geq$ $0.05)$.

For the CBCT measurements (TAD-U3D), the amount of tooth movement in millimeters measured from the TAD to the distal curvature of the canine tooth showed that the mean of all patient measurements on the Propel side is $0.44 \mathrm{~mm}$ less than the control side. The second measured variable (U5M-U3D), the amount of tooth movement in millimeters measured from the outermost mesial curvature of the second premolar to the outermost distal curvature of the canine tooth shows that the mean of all patient measurements on the Propel side is $0.30 \mathrm{~mm}$ greater than the control side. However, there was no significant difference between the Propel side and the Control side for both measurements (Figure 4).

Canine retraction was also measured on the digital models using OrthoCAD 3.5 (Cadent $\left.^{\mathrm{Tw}}\right)$ software at $\mathrm{T}_{0}$ and $\mathrm{T}_{1}$. Comparisons were made for each category at $\mathrm{T}_{0}$ and $\mathrm{T}_{1}$ on both experimental and control sides. For U3 Cusp Tip- U5 Cusp Tip, the amount of tooth movement in millimeters measured from the cusp tip of the canine to the cusp tip of the second premolar shows that the mean of all patient measurements on the Propel side is $0.14 \mathrm{~mm}$ greater than the control side in average. For U5M-U3D, the amount of tooth movement in millimeters measured from the outermost mesial curvature of the second premolar to the outermost distal curvature of the canine shows that the mean of all patient measurements on the Propel side is $0.24 \mathrm{~mm}$ less than the control side in average. For U2 Midpoint-U3 Cusp Tip, the amount of tooth movement in millimeters measured from a midpoint on the incisal edge of the lateral incisor to cusp tip of the canine shows that the mean of all patient measurements on the Propel side is $0.24 \mathrm{~mm}$ greater than the control side in average. For U6 MP Cusp Tip-U3 Cusp Tip, the amount of tooth movement in millimeters measured from the mesio-palatal cusp tip of the first molar to the cusp tip of the canine shows that the mean of all patient measurements on the Propel side is $0.18 \mathrm{~mm}$ greater than the control side in average. However, there was no significant difference between the Propel side and the Control side on all variables measured on the digital models $(\mathrm{p} \geq 0.05)$ (Figure 5).

Five study subjects, four female patients and one male patient, showed more canine retraction on the experimental side than the control side but the overall amount of canine retraction on the experimental side with micro-osteoperforations on all subjects was not statistically significant when compared with the control side $(\mathrm{P}>0.05)$ (Table 3). 

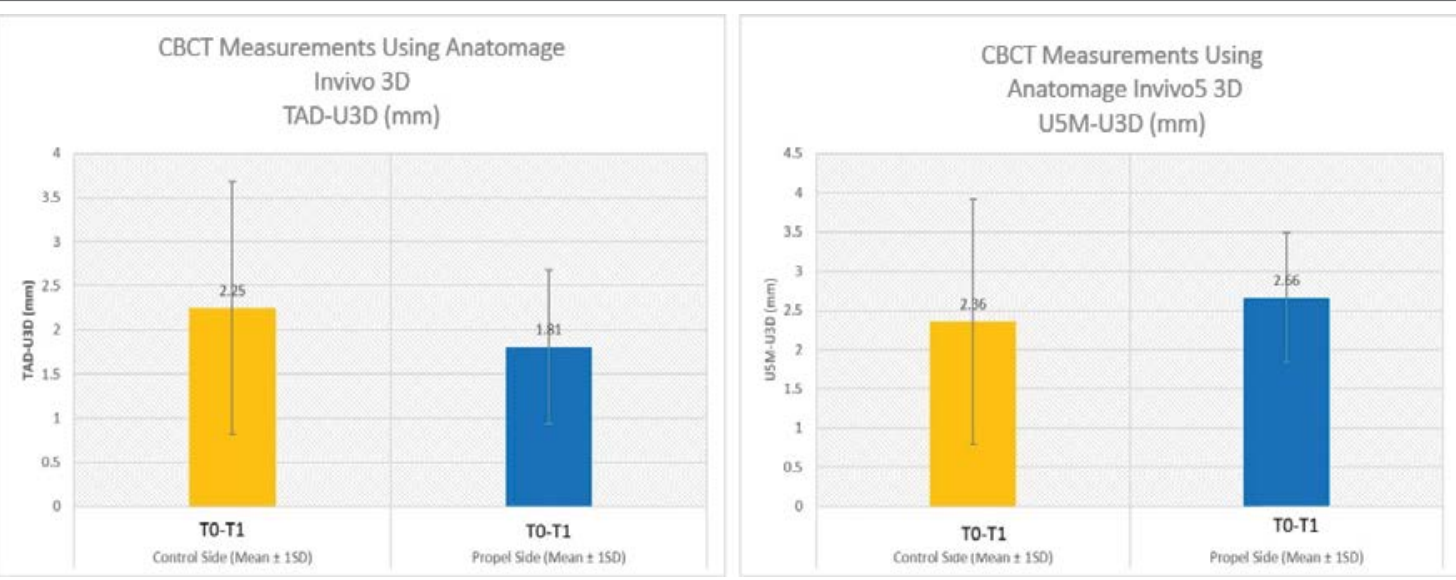

Figure 4: Graphs showing the mean of all patients' measurements for СВCT.

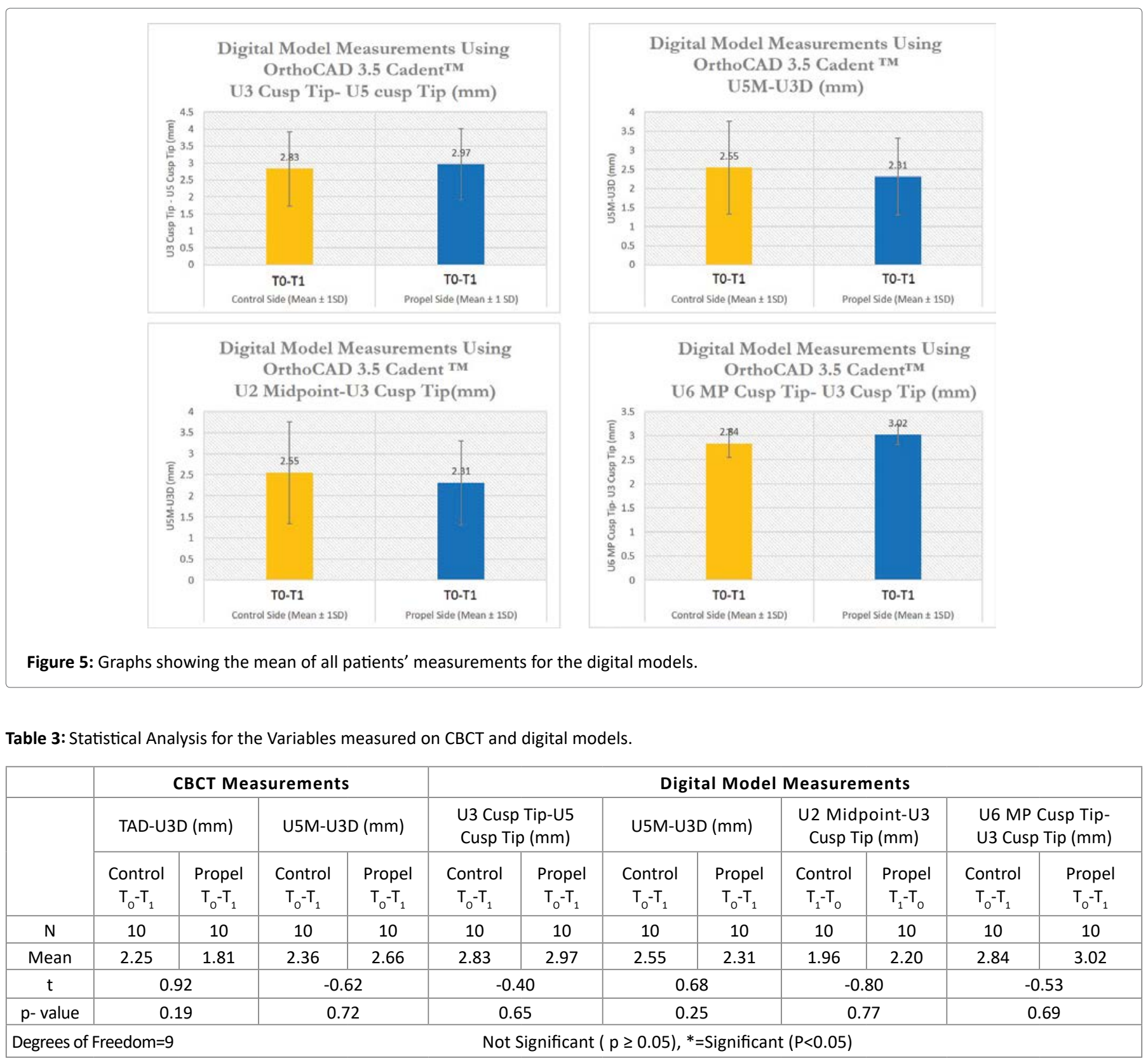




\section{Discussion}

The objective of this study was to determine whether microosteoperforations of the cortical bone produce 'clinically meaningful' accelerated tooth movement during space closure in adult patients. In an attempt to eliminate inter-subject variability and due to a smaller sample size, a split-mouth study was designed for this clinical research project [20-22].

In Rapid Acceleratory Phenomenon (RAP), surgical wounding of the cortical bone increases the rate of bone remodeling by increasing bone turnover and decreasing bone density in the surroundings of the surgical site [5]. Bone remodeling is an inflammatory phenomenon that depends on the expression of cytokines and inflammatory markers. After forces are applied on a tooth, expression of cytokines such as IL- $1 \beta$, TNF- $\alpha$, IL-6, and IL- 8 increases that in turn leads to osteoclast differentiation and activation of bone remodeling and tooth movement $[19,23]$. There are a few animal research studies reporting an increase in the rate of tooth movement when micro-osteoperforations of the bone are performed [17,18]. Alkhalani, et al. reported in 2013 [19] that micro-osteoperforations can increase the rate of canine retraction by more than 2 -fold in orthodontic adult patients. In our study, each of the research subjects responded differently to the microosteoperforations with varied amount of canine retraction into the extraction space. The overall amount of canine retraction was not statistically different between the experimental side and the control side at $\mathrm{T}_{1}$ for any variables. The results of this study indicate that five study subjects showed more canine retraction on the experimental side but the overall rate of canine retraction was not significantly different between the experimental side and the control side for all the measured variables.

The goal of the study design was to minimize the effects of factors that could change the outcome of this study; a split mouth design was chosen to eliminate the bias originated from a smaller sample size and biological variabilities in individual subjects. Healthy adult subject's age's 18-37 years old with similar malocclusion were selected in an attempt to homogenize the age-related influences involved in the rate of tooth movement but it can be argued that the biology of tooth movement in the selected age group can still be different for each subject. For instance, the rate of tooth movement may be faster in an 18 year old in comparison to a 37 year old. Similarly, efforts were made to minimize the operator-related errors in detection of the canine and second premolar cusp tips but in some study subjects with attrition, it was challenging to eliminate these types of variabilities. The factors that could potentially affect the rate of tooth movement can include but are not limited to individual variations in basal metabolism, gender and hormonal changes, forces of occlusion, and patient's health issues requiring medication therapy that were not disclosed during the period of the research study.

The biological response of the cortical bone to force can be different in individuals leading to variable amount of tooth movement in each study subject. The purpose of using the Propel device is to create a "localized" area of trauma that leads to activation of an inflammatory process (RAP) and accelerated tooth movement but it is not clear if the inflammation actually stays localized or spreads. The biological factors that can potentially alter the result of the study are yet to be determined and discussed. Research supports the role of inflammation in accelerating orthodontic tooth movement, but the findings of this study are in line with one of the latest systematic review performed by Rozen et al. [23]. They determined that all the studies that have been produced on this timely topic in the recent years have "potentially invalidating evidence and description of new methods"; for that reason, there is a need for more research studies and a new systematic review on adjunct procedures including accelerated tooth movement by Propel.

There are many different, innovative, and appealing orthodontic methods suggested by the competing manufacturers to reduce the treatment time in adult patients; however, orthodontists must carefully examine each method and be cautious when interpreting and conveying that knowledge to his/her patients. Propel Orthodontics advocates considerably faster tooth movement and shorter treatment time in adult patients when the Propel Excellerator and Propel Excellerator RT are used to perform micro-osteoperforations in the cortical bone. Our population did not replicate the findings noted in the previous study and no significant differences were observed between the experimental and the control side when the overall amount of canine retraction was considered. At this time, the evidence from our study is not compelling. Considering a recent review which supported both corticotomy with flap and piezocision procedure [24,25], more research is needed to obtain a better understanding of the effects of micro-osteoperforations on the rate of orthodontic tooth movement.

\section{Conclusions}

The purpose of the present study was to determine whether micro-osteoperforations of the cortical bone increase rate of tooth movement in adult patients. The results of this split mouth study indicate that canine retraction is very variable on the experimental side when compared to the control side over the treatment time and the increase in the rate of tooth movement was not significantly different in the overall sample. Although, micro-osteoperforations can cause an inflammatory response in the cortical bone, additional research studies are necessary to evaluate and confirm their positive effect on the rate of tooth movement in the orthodontic treatment of adult patients. Therefore, a skilled clinician should be judicious when introducing micro-osteoperforations of the bone to their adult patient as an effective method to decrease treatment time.

\section{Acknowledgements}

We are deeply in debt to American Association of Orthodontists Foundation (AAOF) for their support and providing the financial means to perform this research study.

Thanks to Dr. Jeffrey Price for his continuous help with Anatomage Invivo 5 3D software training.

\section{References}

1. Oppenheim A (1930) Bone changes during tooth movement. International Journal of Orthodontia, Oral Surgery and Radiography 16: 535-551.

2. Frost HM (1981) The Regional accelerated phenomenon. Orthop Clin N Am 12: 725-726.

3. Köle H (1959) Surgical operations on the alveolar ridge to correct occlusal abnormalities. Oral Surg Oral Med Oral Pathol 12: 515-529.

4. Alhashimi N, Frithiof L, Brudvik P, Bakhiet M (2000) Orthodontic movement induces high numbers of cells expressing IFN-gamma at mRNA and protein levels. J Interferon Cytokine Res 20: 7-12.

5. Ren A, Lv T, Kang N, Zhao B, Chen Y, et al. (2007) Rapid orthodontic tooth movement aided by alveolar surgery in beagles. Am J Orthod Dentofacial Orthop 131: 160.e1-160.e10.

6. Krishnan V, Davidovitch Z (2006) Cellular, molecular, and tissue-level reactions to orthodontic force. Am J Orthod Dentofacial Orthop 129: 469.e1-469.e32. 
7. Teixeira CC, Khoo E, Tran J, Chartres I, Liu Y, et al. (2010) Cytokine expression and accelerated tooth movement. J Dent Res 89: 11351141.

8. Kim YS, Kim SJ, Yoon HJ, Lee PJ, Moon W, et al. (2013) Effect of piezopuncture on tooth movement and bone remodeling in dogs. Am J Orthod Dentofacial Orthop 144: 23-31.

9. Bartzela T, Türp JC, Motschall E, Maltha JC (2009) Medication effects on the rate of orthodontic tooth movement: a systematic literature review. Am J Orthod Dentofacial Orthop 135: 16-26.

10. de Llano-Perula MC, Iglesias-Linares A (2015) Surgically-based methods to modify orthodontic tooth movement: A literature review. Edorium J Dent 2: 35-42.

11. Cassetta M, Di Carlo S, Giansanti M, Pompa V, Pompa G, et al. (2012) The impact of osteotomy technique for corticotomy-assisted orthodontic treatment (CAOT) on oral health-related quality of life. Eur Rev Med Pharmacol Sci 16: 1735-1740.

12. Cruz DR, Kohara EK, Ribeiro MS, Wetter NU (2004) Effects of lowintensity laser therapy on the orthodontic movement velocity of human teeth: a preliminary study. Lasers Surg Med 35: 117-120.

13. Dibart S, Sebaoun JD, Surmenian J (2009) Piezocision: a minimally invasive, periodontally accelerated orthodontic tooth movement procedure. Compend Contin Educ Dent 30: 342-344, 346, 348-350.

14. Kharkar VR, Kotrashetti SM (2010) Transport dentoalveolar distraction osteogenesis-assisted rapid orthodontic canine retraction. Oral Surg Oral Med Oral Pathol Oral Radiol Endod 109: 687-693.

15. Wilcko WM, Wilcko T, Bouquot JE, Ferguson DJ (2001) Rapid orthodontics with alveolar reshaping: two case reports of decrowding. Int J Periodontics Restorative Dent 21: 9-19.
16. Yassaei S, Fekrazad R, Shahraki N (2013) Effect of Low Level Laser Therapy on Orthodontic Tooth Movement: A Review Article. J Dent (Tehran) 10: 264-272.

17. Nishimura M, Chiba M, Ohashi T, Sato M, Shimizu $Y$, et al. (2008) Periodontal tissue activation by vibration: intermittent stimulation by resonance vibration accelerates experimental tooth movement in rats. Am J Orthod Dentofacial Orthop 133: 572-583.

18. Tsai CY, Yang TK, Hsieh HY, Yang LY (2016) Comparison of the effects of micro-osteoperforation and corticision on the rate of orthodontic tooth movement in rats. Angle Orthod 86: 558-564.

19. Alikhani M, Raptis M, Zoldan B, Sangsuwon C, Lee YB, et al. (2013) Effect of micro-osteoperforations on the rate of tooth movement. Am J Orthod Dentofacial Orthop 144: 639-648.

20. Chang HW, Huang HL, Yu JH, Hsu JT, Li YF, et al. (2012) Effects of orthodontic tooth movement on alveolar bone density. Clin Oral Investig 16: 679-688.

21. Duker J (1975) Experimental animal research into segmental alveolar movement after corticotomy. J Maxillofac Surg 3: 81-84.

22. Pandis N, Walsh T, Polychronopoulou A, Katsaros C, Eliades T (2013) Split-mouth designs in orthodontics: an overview with applications to orthodontic clinical trials. Eur J Orthod 35: 783-789.

23. Rozen D, Khoo E, El Sayed H, Niedermanb R, Mc Gowanc R, et al, (2015) Accelerated tooth movement: Do we need a new systematic review? Semin Orthod 21: 224-230.

24. Hassan AH, Al-Saeed SH, Al-Maghlouth BA, Bahammam MA, Linjawi $\mathrm{Al}$, et al. (2015) Corticotomy-assisted orthodontic treatment. A systematic review of the biological basis and clinical effectiveness. Saudi Saudi Med J 36: 794-801.

25. Viwattanatipa N, Charnchairerk S (2018) The effectiveness of corticotomy and piezocision on canine retraction: A systematic review. Korean J Orthod 48: 200-211. 